\title{
Does continuous interscalene nerve blockage delay discharge following minimal invasive shoulder surgery?
}

\author{
John R Cormack ${ }^{1}$, Cristian Udovicich², Martin Richardson ${ }^{2}$ \\ 1. Dept of Anesthesia Epworth Hospital, Richmond, Australia. 2. Dept of Orthopedic Surgery Epworth Hospital, Richmond, \\ Australia.
}

Correspondence: John R Cormack. Address: 7/13 Brunswick St. Fitzroy, Melbourne 3065, Australia. E-mail: cormackj@ozemail.com.au

Received: July 31, 2013

DOI : 10.5430/jha.v3n1p41
Accepted: September 9, 2013 Online Published: September 29, 2013

URL: http://dx.doi.org/10.5430/jha.v3n1p41

\section{Abstract}

Background: When compared with single shot interscalene nerve blockade (SSISB), continuous interscalene nerve blockade (CISNB) has previously been shown to decrease pain and narcotic requirement following open shoulder surgery including arthroplasty and rotator cuff repair. Advances in surgery have allowed many shoulder operations to be performed arthroscopically or via a "mini open” approach. This study investigates whether continuous nerve blockade provides a difference in recovery parameters sufficient to impact discharge time following surgery when compared with a single dose nerve block.

Methods: This was a retrospective case-control series. The hospital records of consecutive arthroscopic or mini open shoulder operation patients were examined and divided into those given CISNB $(n=94)$ and those given SSISB $(n=77)$ for post operative analgesia. Groups were compared for time to discharge in a private hospital setting in which strict discharge protocols were not in place. Narcotic use and maximal visual analogue scale (VAS) pain score were also recorded.

Results: Length of stay was statistically significantly different between the two groups. Patients in the CISNB group had a median length of stay of 24.5 hours (IQR 20.8-42.0) compared to 23.0 hours (18.8-40.5) in the SSISB group $(p=.03)$. CISNB group patients had decreased narcotic use. No difference in maximal VAS pain score was identified.

Conclusion: With greater emphasis on non-invasive approaches to shoulder surgery, patients are able to be discharged at a time acceptable to both physician and patient regardless of the presence of CISNB. Surprisingly the CISNB group had a longer length of stay (although from a practical sense similar). The advantages of this analgesic technique in terms of improved pain relief and decreased narcotic use do not affect hospital length of stay. Level III evidence.

\section{Key words}

Interscalene nerve block, Continuous nerve blockade, Arthroscopic shoulder surgery, Discharge time, Recovery 


\section{Introduction}

Discharge planning and bed utilization are vital topics for hospital administrators and unit managers alike. Information concerning anticipated length of stay for a particular patient undergoing a common operation is of interest to those balancing bed occupancy.

Despite the proven advantages of continuous peripheral nerve blockade, including continuous interscalene nerve blockade (CISNB), in many areas of post operative care, the benefits following minor shoulder surgery in a private hospital setting are less obvious, perhaps explaining the relatively small number of anesthetists routinely choosing this technique for post operative analgesia in Australia.

Recent studies have proven the safety and efficacy of same day surgery (SDS) with continuous peripheral nerve blockade ${ }^{[1]}$ including patients who have had arthroscopic shoulder surgery ${ }^{[2,3]}$. Success for the practice of discharge home with a perineural infusion in situ has been achieved with a high degree of organization, incorporating extensive patient education and post operative review either by telephone or a direct out of hospital visit. Rarely patients have required return to hospital to reestablish a block or admission ${ }^{[1]}$. However, the real possibility exists that the duration of blockade may exceed the presence of pain for some patients as this can be extremely variable between patients.

This retrospective study specifically looked at time from completion of surgery to discharge of all consecutive patients operated on by a single orthopedic surgeon, having elective minimally invasive shoulder surgery and compared those having CISNB in one group with those having single shot interscalene nerve blockade (SSISB).

\section{Materials and methods}

Following institutional ethics committee approval, medical records were examined of all patients who had undergone: arthroscopic acromioplasty, arthroscopic and mini-open rotator cuff repair, arthroscopic capsulotomy and "Superior Labrum from Anterior to Posterior" (SLAP) repair in an 18 months period. Exclusions were patients with ASA status greater than 3, age less than 16 years, emergency surgery and bilateral surgery (as bilateral blockade is not recommended). Patients who did not receive CISNB or SSISB were also not included. Review of the post operative notes determined that in no case was patient discharge delayed by an intercurrent medical problem. Time to discharge was taken as the time from the end of surgery until recorded time of discharge from the ward.

Two anesthetists in the CISNB group and twelve anesthetists in the SSISB group provided analgesia for all of the patients within this single private hospital during the retrospective period. All patients had a general anesthetic with the individual anesthetists determining the drugs used. Patients in both groups were provided parenteral and oral analgesics on an "as required basis" as well as parenteral antiemetics as required. There was no targeted discharge time, as this is routinely left to the patient's discretion and nursing initiated discharge planning provided they were able to ambulate and void and that pain and nausea had been controlled. Both groups had the block performed prior to surgery under intravenous sedation. In the CISNB group, a Pajunck Plexalong $50 \mathrm{~mm}$ facet tipped stimulating needle was used and the initial block was established with $20 \mathrm{ml}$ of $0.75 \%$ ropivacaine inserted through the needle. Stimulation of triceps, biceps or deltoid muscle with currents of $0.3 \mathrm{~mA}-0.6 \mathrm{~mA}$ were accepted using a Pajunck Multistimuplex nerve stimulator at $2 \mathrm{~Hz}$. Inadequate blocks were augmented in the post anesthetic care unit with a further $10 \mathrm{ml} 0.75 \%$ ropivacaine through the catheter and an infusion of $0.2 \%$ ropivacaine was commenced in all CISNB patients at $8 \mathrm{ml}-10 \mathrm{ml}$ per hour either via an electronic pump or an elastomeric pump (C-Bloc-surgical specialties). Patients with an electronic pump were allowed boluses of $5 \mathrm{ml}$ each hour (maximum of $6 \mathrm{ml}$ per 24 hour period) and a rate increase up to $14 \mathrm{ml}$ per hour, and those with an elastomeric pump were allowed rate increases to $14 \mathrm{ml}$ per hour without the bolus option. Each patient in the CISNB series was reviewed by the anesthetist on the night of surgery and again early in the morning. In two cases, the patients were discharged home prior to their review but after removal of the catheter. 
Patients in the SSISB group received ropivacaine $0.75 \%$ through a stimuplex (Braun) needle with placement guided by either nerve stimulator or ultrasound. They were not reviewed by the anesthetist the next day and their discharge plans were determined by agreement between patient, surgeon and nursing staff with oral analgesics prescribed.

Secondary endpoints also derived from patient records included maximal visual analogue scale (VAS) score and total morphine equivalents post surgery and prior to discharge. Morphine equivalents have been estimated according to schedule described in Fredrickson's study ${ }^{[4]}$.

\section{Statistical analysis}

Data was entered into Microsoft Excel (2010, Microsoft, USA). All statistical analyses were conducted using Stata (12.0, Stata Corp, USA). A statistician from the university teaching hospital was involved before and after data collection. Data is presented as mean (95\% confidence interval), median (interquartile range) or absolute (percent). Data was statistically evaluated using the Fisher Exact Test, Student T-Test or Mann-Whitney U-Test, where appropriate. The Mann-Whitney U-test was used for the analysis of the primary outcome of duration due to the skewed nature of distribution.

\section{Results}

A total of 229 minor shoulder procedures were identified during the eighteen month period. Fourteen patients did not meet the inclusion criteria. A further 44 received anesthesia other than CISNB or SSISB. In total, 171 patients were finally included for analysis. There were 94 patients who received CISNB and 77 patients who received SSISB.

Patient demographics and surgical data are presented in tables 1 and 2. Age, gender, BMI and surgical data were well matched between the CISNB and SSISB groups.

Table 1. Patient demographics

\begin{tabular}{llll}
\hline & CISNB (n = 94) & SSISB $(\mathbf{n}=77)$ & $p$ value \\
\hline Age & $50.9(48.3-53.4)$ & $52.4(49.8-55.0)$ & .41 \\
Gender (M/F) & $46 / 48(49 / 51 \%)$ & $45 / 32(58 / 42 \%)$ & .22 \\
BMI & $27.3(26.1-28.4)$ & $27.7(26.4-29.1)$ & .61 \\
& & & \\
I & ASA Status & .001 \\
II & $59(63 \%)$ & $28(36 \%)$ & .32 \\
III & $26(28 \%)$ & $27(35 \%)$ & $<.001$ \\
Missing Data & $4(4 \%)$ & $19(25 \%)$ & .73 \\
\hline
\end{tabular}

Note. Data presented as mean $(95 \% \mathrm{CI})$ or number of patients (percent). ASA Status: American Society of Anesthesiologists physical status classification system.

Table 2. Surgical data

\begin{tabular}{llcc}
\hline & CISNB (n = 94) & SSISB (n = 77) & $p$ value \\
\hline Shoulder (Left/Right) & $43 / 51(46 / 54 \%)$ & $33 / 44(43 / 57 \%)$ & .75 \\
& \multicolumn{2}{c}{ Type of Shoulder Surgery } & .35 \\
Acromioplasty & $38(40 \%)$ & $37(48 \%)$ & .59 \\
Capsulotomy & $23(24 \%)$ & $16(21 \%)$ & .52 \\
SLAP Repair & $7(7 \%)$ & $3(4 \%)$ & .99 \\
Rotator Cuff Repair & $26(28 \%)$ & $21(27 \%)$ & \\
\hline
\end{tabular}

Note. Data presented as number of patients (percent). SLAP: superior labral tear from anterior to posterior. 
Primary and secondary outcomes are presented in table 3. Median length of stay was statistically significantly longer for the CISNB group compared with the SSISB group with a 1.5 hour difference. Patients in the CISNB group had a length of stay of 24.5 hours (IQR 20.8-42.0) compared to 23.0 hours (IQR 18.8-40.5) in the SSISB group ( $p=.03$ ). Both groups also had similar proportions of patients requiring length of stay greater than 48 hours with $12 \%$ in the CISNB group and $8 \%$ in the SSISB group $(p=.45)$.

Table 3. Outcomes

\begin{tabular}{llll}
\hline & CISNB (n = 94) & SSISB (n = 77) & $\boldsymbol{p}$ value \\
\hline Length of Stay (hours) & $24.5(20.8-42.0)$ & $23.0(18.8-40.5)$ & .03 \\
LOS > 48 h & $11(12 \%)$ & $6(8 \%)$ & .45 \\
Narcotic Use (mg) & $2(0-8)$ & $5(0-14)$ & .05 \\
Maximal VAS Pain Score & $2(0-4)$ & $2(0-5)$ & .56 \\
\hline
\end{tabular}

Note. Data presented as median (interquartile range) or number of patients (percent). Narcotic use: morphine equivalents. VAS: Visual Analogue Scale (Least Severe 1-Most Severe 10).

Median narcotic use was significantly increased in the SSISB group with patients requiring $5 \mathrm{mg}$ morphine equivalent (IQR 0-14) compared to $2 \mathrm{mg}$ (IQR $0-8$ ) in the CISNB group ( $p=.05$ ). No difference in median maximal VAS pain score was reported across both groups with CISNB patients reporting 2 (IQR 0-4) and SSISB patients reporting 2 (IQR 0-5) $(p=.56)$.

\section{Discussion}

From our study, it appears that factors other than the presence of continuous interscalene nerve blockade are dominant in determining time to discharge following minimally invasive shoulder surgery. Although the analysis showed a statistically increased length of stay in the CISNB group, from a practical point of view the median times were very similar. We specifically targeted less invasive (and less traumatic) procedures, as advantages of CISNB in shoulder arthroplasty has already been addressed by Ilfeld et al. confirming a shorter hospital stay in this group when CISNB is used on an ambulatory basis ${ }^{[3]}$. Alternatively there is a published series ${ }^{[5]}$ of patients discharged home on the same day having had a single shot interscalene block without a catheter. This leaves us with the questions: although discharge with an interscalene catheter is safe and feasible, is it necessary (or desired) for all shoulder surgery including an increasing array of minimally invasive approaches to previously open operations, and if it is necessary for how long? An editorial addressing a similar discussion was published in Anesthesia in 2010 by Hadzic, Gadsen and Shariat ${ }^{[6]}$. They state that despite some authors' enthusiasm for CISNB in all forms of shoulder surgery, a meta-analysis is not possible due to lack of studies fitting the quality criteria. A review of the literature by Fredrickson et al. ${ }^{[7]}$ reports better outcomes (pain score and analgesic consumption) in the first 24 hours with CISNB, however these benefits seemed less apparent from the second day onwards. This would seem to also be the case with our data which combined a more heterogeneous group of minor to moderate arthroscopic and mini open surgery. It appears that a modest difference in pain scores and analgesic requirements makes little difference to the patients' ability to tolerate discharge home.

This study has several limitations. Specifically the retrospective nature of the study makes it difficult to make clear statements regarding the secondary endpoints of morphine equivalents and VAS score, which were also recorded irregularly at times. Rather these were included as a means of validating the effectiveness of the CISNB group compared with other studies and confirming previously proven superiority in terms of analgesia in our series. Yet despite these findings we show an increase in length of stay with CISNB. Although a power analysis was not performed, the numbers chosen far exceeded those in a comparable study of shoulder arthroplasty which showed a significant difference in favour of CISNB ${ }^{[3]}$. Other limitations include the variability of the patients and operations performed and various social factors which may affect time to discharge such as distance from hospital and age. Despite the fact that there were no absolute 
administrative drivers for discharge times, there are implicit usual standards which nurse unit managers may consciously or subconsciously strive towards. In this hospital the health funds do not determine length of stay primarily.

In favor of the study providing a true representation of difference between discharge times is the fact that the two groups were well matched demographically. The same surgeon performed all of the operations and the nursing staff and policies were constant throughout all cases in the orthopedic ward of a private hospital. The primary end point was the time from end of surgery to discharge, which was found to be reliable data available in every patient with predictable accuracy. The vast majority of CISNBs were performed by a single anesthetist with an experience of over 500 catheters. In our series, CISNB was successful in all cases either with the initial block or with a "through catheter top up".

There are significant new directions being taken in the management of discharge following shoulder surgery. Several centers in different countries have published on the results of ambulatory interscalene infusions associated with earlier (within 24 hours) discharge from the hospital ${ }^{[1,2]}$. In Fredrikson's series discharge occurred within the 24 hours "unless prevented by social circumstances" and similarly in our group several patients chose to remain in hospital for reasons other than superior pain control management. Also, several patients chose for the catheters to be removed rather than have the block reestablished despite pain, due to concern about excessive motor and sensory block particularly if it included the hand.

It is interesting to note that although there were no significant complications from the interscalene catheters in the current study, the author reviewed each patient in hospital on the day of surgery and the following morning and noted a side effect profile which has previously been outlined in other studies. Recurrent laryngeal nerve palsy was present occasionally, and phrenic nerve palsy leading to a sensation of dyspnoea led to patient request for removal on two occasions. These fairly innocent, but potentially worrying problems were all dealt with by nursing staff on the ward, all of whom had been appropriately educated and had a comprehensive protocol for guidance. Other studies have dealt with these problems over the phone or by reviewing the patient back in the hospital for re-establishment of block or intravenous narcotics following catheter dislodgement ${ }^{[1,2]}$. Although these events seem rare they can be inconvenient to an anesthetist at a remote location particularly after hours. In our series there was no incidence of being asked to review the patient outside of the two scheduled visits.

\section{Conclusion}

This retrospective study examining the comparative length of stay following minor to moderate minimally invasive shoulder surgery with continuous interscalene nerve blockade versus single shot interscalene block further questions the justification and need for the technique beyond the first 24 hours. Our findings support the editorial comments by Hadzic et al. calling for further studies to better define the types of minimally invasive surgery where continuous techniques offer a definite advantage.

\section{Acknowledgement}

Many thanks to Helen Barton for her help with patient records and Dr. Roman Kluger for his help with the statistical analysis.

\section{References}

[1] Swenson, J. D., et al. Outpatient management of continuous peripheral nerve catheters placed using ultrasound guidance: an experience in 620 patients. Anesth. Analg. [Internet] 2006; 103, 1436-1443. Available from: http://www.anesthesia-analgesia.org/content/103/6/1436.abstract. PMid: 17122219. http://dx.doi.org/10.1213/01.ane.0000243393.87912.9c 
[2] Fredrickson, M. J., Ball, C. M., Dalgleish, A. J. Successful Continuous Interscalene Analgesia for Ambulatory Shoulder Surgery in a Private Practice Setting. Reg. Anesth. Pain Med. [Internet] 2008; 33, 122-128. Available from:

http://journals.lww.com/rapm/Abstract/2008/03000/Successful_Continuous_Interscalene_Analgesia_for.6.aspx. PMid: 18299092.

[3] Ilfeld, B. M., et al. Ambulatory continuous interscalene nerve blocks decrease the time to discharge readiness after total shoulder arthroplasty: a randomized, triple-masked, placebo-controlled study. Anesthesiology. [Internet] 2006; 105, 999-1007. Available from:

http://journals.lww.com/anesthesiology/Fulltext/2006/11000/Ambulatory_Continuous_Interscalene_Nerve_Blocks.22.aspx. PMid: 17065895. http://dx.doi.org/10.1097/00000542-200611000-00022

[4] Fredrickson, M. J., Stewart, A. Continuous interscalene analgesia for rotator cuff repair: a retrospective comparison of effectiveness and cost in 205 patients from a multi-provider private practice setting. Anaesth. Intensive Care. [Internet] 2008; 36, 786-791. Available from: http://www.aaic.net.au/Document/?D=20080263. PMid: 19115645.

[5] Faryniarz, D., et al. Interscalene block anesthesia at an ambulatory surgery center performing predominantly regional anesthesia: A prospective study of one hundred thirty-three patients undergoing shoulder surgery. J. Shoulder Elbow Surg. [Internet] 2006; 15, 686-690. Available from: http://www.jshoulderelbow.org/article/S1058-2746(06)00089-9/abstract. PMid: 16949840. http://dx.doi.org/10.1016/j.jse.2006.02.001

[6] Hadzic, A., Gadsden, J., Shariat, A. N. Local and nerve block techniques for analgesia after shoulder surgery. Anaesthesia. [Internet] 2010; 65, 547-548. Available from: http://onlinelibrary.wiley.com/doi/10.1111/j.1365-2044.2010.06385.x/abstract. PMid: 20565389. http://dx.doi.org/10.1111/j.1365-2044.2010.06385.x

[7] Fredrickson, M. J., Krishnan, S., Chen, C. Y. Postoperative analgesia for shoulder surgery: a critical appraisal and review of current techniques. Anaesthesia. [Internet] 2010; 65, 608-624. Available from: http://onlinelibrary.wiley.com/doi/10.1111/j.1365-2044.2009.06231.x/abstract. PMid: 20565394.

http://dx.doi.org/10.1111/j.1365-2044.2009.06231.x 